\section{FORTRAN IV functions for calculating probabilities associated with Dunnett's test}

\author{
WILLIAM P. DUNLAP, MARCIA S. MARX, \\ and GREGORY J. AGAMY \\ Tulane University, New Orleans, Louisiana 70118
}

the probabilities of Dunnett's distribution in the following form:

$$
\begin{aligned}
& 1-F(t / d f ; k ; r)= \\
& \int_{0}^{\infty}\left\{\int_{-\infty}^{\infty}\left[E\left(\frac{r^{1 / 2} x+t s}{(1-r)^{1 / 2}}\right)-E\left(\frac{r^{1 / 2} x-t s}{(1-r)^{1 / 2}}\right)\right]^{k} z(x) d x\right\} g(s ; d f) d s,
\end{aligned}
$$

where

$$
\begin{aligned}
& z(x)=\frac{1}{\sqrt{2 \pi}} e^{-x^{2} / 2} . \\
& E(u)=\int_{-\infty}^{\infty} z(u) d u,
\end{aligned}
$$

and

$$
g(s ; d f)=\frac{d f d f / 2}{\Gamma(d f / 2) 2^{d f / 2-1}} s^{d f-1} e^{-d f s^{2} / 2}
$$

The function $z(x)$ is the equation for ordinates of the nominal curve. The integral, $\mathrm{E}(\mathrm{t})$, is the cumulative probability of a standard normal deviate that is solved by the probability function provided in Dunlap and Duffy (1975). Since extreme normal deviates are encountered, this function is augmented by another approximation for extreme scores provided by Zelen and Severo (1965, p. 933, Function 26.2.24).

The inner integral of the top expression is solved numerically with about 20 points using Simpson's rule. Since the distribution integrated is symmetric, the program calculates the area from 0 to infinity and then doubles this amount. The solution to this inner integral gives probability values of Dunnett's test when the degrees of freedom, df, are infinite. In practice, the program solves this inner integral only whenever the degrees of freedom exceed 2,000.

The outer integral studentizes Dunnett's test; that is, it adjusts the distribution for finite degrees of freedom associated with the error term. The function $\mathrm{g}(\mathrm{s} ; \mathrm{df})$ is the distribution of the ratio of the sample to the population standard deviation, and it is not symmetric; therefore, the integration is done in two parts, from the modal value 1 to infinity and then from 1 to 0 . This integration involves from 24 to 30 points fitted with Simpson's rule.

The first input parameter for the function is the Student $t$ statistic, calculated in the usual manner:

$$
\mathrm{t}=\left(\overline{\mathrm{X}}_{\mathrm{c}}-\overline{\mathrm{X}}_{\mathrm{E}}\right) /\left(\mathrm{S} \sqrt{1 / \mathrm{N}_{\mathrm{c}}+1 / \mathrm{N}_{\mathrm{E}}}\right),
$$

where $\bar{X}_{c}$ and $\bar{X}_{e}$ are the control and experimental means, $N_{c}$ and $N_{E}$ are the respective sample sizes, and $S$ 
is the estimated common standard deviation. Usually, the square root of the mean square error from an analysis of variance involving all groups is used to estimate $S$. The second parameter, $\mathrm{df}$, is the degrees of freedom associated with $S$ (equal to the df error from the analysis of variance). The third input parameter, $\mathrm{K}$, is the number of experimental group means, excluding the control mean. The last parameter, $r$, is the correlation between contrasts, calculated as

$$
r=N_{E} /\left(N_{E}+N_{c}\right) \text {, }
$$

which clearly equals .5 for equal sample sizes, but which will be less than .5 for proportionally larger $\mathrm{N}_{\mathrm{c}}$. For a more complete description and a worked example of Dunnett's test, see Edwards (1968).

Accuracy. The probabilities produced by the function agree to as many places of accuracy as are available in any of the published tables of Dunnett's test. Thus the calculations are accurate to at least the fourth decimal place. The inaccuracy introduced by switching to the asymptotic distribution for degrees of freedom greater than 2,000 is in the fourth decimal place and so should not present much problem to the practical user.

Time Requirements. Because two nested integrals are solved numerically, with approximately $600(20 \times 30)$ points, the time required to find each probability value is rather long; however, run time does not vary greatly as a function of the parameters used. On a DEC-20 computer, the average time for each probability calculation is in the neighborhood of $.70-.85 \mathrm{sec}$.

Program Availability. The working part of the program is written as a series of four function subprograms in standard single-precision FORTRAN IV and runs on a DEC-20 computer. Since the language is standard, these functions should run without change on any machine that has a FORTRAN IV compiler. A nine- statement main routine to operate the functions is also included at the front and contains some FORTRAN statements peculiar to the DEC system; however, the users of these functions will probably wish to write their own main routines, depending upon the particular use they have in mind.

There are no special peripheral requirements; memory size need only be sufficient to load the function and a main routine to call it. A listing of the function may be obtained at no cost from William P. Dunlap, Department of Psychology, Tulane University, New Orleans, Louisiana 70118.

\section{REFERENCES}

DunlaP, W. P., \& Dufry, J. A. FORTRAN IV functions for calculating exact probabilities associated with $\mathrm{z}$, chi-square, $\mathrm{t}$, and F values. Behavior Research Methods \& Instrumentation, $1975,7,59-60$.

Dunlap, W. P., Powell, R. S., \& Konnerth, T. K. A FORTRAN IV function for calculating probabilities associated with the studentized range statistic. Behavior Research Methods \& Instrumentation, 1977, 9, 373-375.

DUNNETT, C. W. A multiple comparison procedure for comparing several treatments with a control. Journal of the American Statistical Association, 1955, 50, 1096-1121.

DunNeTt, C. W. New tables for multiple comparisons with a control. Biometrics, 1964, 20, 482-491.

EDWARDS, A. L. Experimental design in psychological research (3rd ed.). New York: Holt, Rinehart, \& Winston, 1968.

Hahn, G. J., \& Hendrickson, R. W. A table of percentage points of the distribution of the largest absolute value of $k$ Student $t$ variates and its applications. Biometrika, 1971, 58, 323-332.

Miller, R. G. Simultaneous statistical inference. New York: McGraw-Hill, 1966.

Shaffer, J. P. Multiple comparisons emphasizing selected contrasts: An extension and generalization of Dunnett's procedure. Biometrics, 1977, 33, 293-303.

Zelen, M., \& Severo, N. C. Probability functions. In M. Abramowitz \& I. A. Stegun (Eds.), Handbook of mathematical functions. New York: Dover, 1965.

Appendix

$\mathrm{C}$

C

C

1

2

3

C

C

C

C

C

TYPE 2

FORMAT ('ENTER Q,DF,K’,\$)

ACCEPT *,Q,DF,K

$\mathrm{R}=.5$

$\mathrm{P}=\mathrm{PDUN}\left(\mathrm{Q}, \mathrm{D}^{\Gamma}, \mathrm{K}, \mathrm{R}\right)$

TYPE 3,P

FORMAT(‘ PROBABILITY =',F12.7)

GOTO 1

END

\section{FUNCTION PDUN(T,D,K,R)}

COMPUTES THE PROBABILITY FOR DUNNETTS TEST

$T=$ STUDENTS $T$ BETWEEN A CONTROL \& EXPERIMENTAL GROUP

$\mathrm{D}=$ DEGREES OF FREEDOM ASSOCIATED WITH T

$\mathrm{K}=$ NUMBER OF EXPERIMENTAL GROUPS (NOT COUNTING CONTROL)

$\mathrm{R}=$ CORRELATION BETWEEN T'S - -0.5 FOR EQUAL $N$

$\mathrm{R}=\mathrm{N}(\mathrm{EXP}) /(\mathrm{N}(\mathrm{EXP})+\mathrm{N}(\mathrm{CONT}))$ FOR UNEQUAL $\mathrm{N}$

PDUN RETURNS WITH TWO TAILED PROBABILITY OF T 
C FOR DF $>2000$ DF IS SET EQUAL TO INFINITY

$\mathrm{C}$

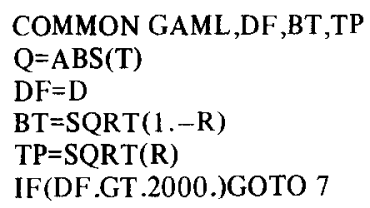

C

C FIND THE LOG OF GAMMA(DF/2.)

C

$\mathrm{X}=\mathrm{DF} / 2$.

GAML=ALOG(SQRT(3.14159))

$\mathrm{N}=\mathrm{X}+.5$

IF(X-FLOAT(N).EQ.0.)GAML=0. IF(X.LE.1.)GO TO 2

DO $1 \mathrm{I}=2 . \mathrm{N}$

$\mathrm{Y}=\mathrm{I}$

$1 \quad$ GAML $=G A M L+A L O G(X-Y+1$.

C

C OUTER INTEGRAL FROM 1 TO INFINITY

C

$2 \quad \mathrm{~A} 1=0.0$

$\mathrm{S}=.14 / \mathrm{SQRT}(\mathrm{DF})$

$\mathrm{X} 0=1$.

$\mathrm{F} 0=\mathrm{DUN}\left(\mathrm{Q}^{*} \mathrm{X} 0, \mathrm{R}, \mathrm{K}\right) * \mathrm{SD}(\mathrm{X} 0)$

$3 \quad \mathrm{X} 1=\mathrm{X} 0+\mathrm{S}$

$\mathrm{F} 1=\mathrm{DUN}\left(\mathrm{Q}^{*} \mathrm{X} 1, \mathrm{R}, \mathrm{K}\right) * \mathrm{SD}(\mathrm{X} 1)$

$\mathrm{X} 2=\mathrm{X} 1+\mathrm{S}$

$\mathrm{F} 2=\mathrm{DUN}(\mathrm{Q} * \mathrm{X} 2, \mathrm{R}, \mathrm{K}) * \mathrm{SD}(\mathrm{X} 2)$

$\mathrm{SUB}=\mathrm{S} / 3{ }^{*}\left(\mathrm{~F} 0+4{ }^{*} \mathrm{~F} 1+\mathrm{F} 2\right)$

$\mathrm{A} 1=\mathrm{A} 1+\mathrm{SUB}$

$\mathrm{X} 0=\mathrm{X} 2$

$\mathrm{F} 0=\mathrm{F} 2$

$\mathrm{S}=\mathrm{S} * 1.05$

IF(A1/SUB.LT.10E7)GOTO 3

C

C OUTER INTEGRAL FROM 1 TO 0

C

$\mathrm{A} 2=0.0$
$S=-.14 / \mathrm{SQRT}(\mathrm{DF})$

$\mathrm{XINC}=1.05$

IF(DF.GT.12.)GOTO 4

$\mathrm{S}=-.03125$

$4 \quad \mathrm{XO}=1$.

$\mathrm{F} 0=\mathrm{DUN}(\mathrm{Q} * \mathrm{X} 0, \mathrm{R}, \mathrm{K}) * \mathrm{SD}(\mathrm{X} 0)$

DO $5 \mathrm{KK}=1,16$

$\mathrm{X} 1=\mathrm{X} 0+\mathrm{S}$

$\mathrm{F} 1=\mathrm{DUN}\left(\mathrm{Q}^{*} \mathrm{X} 1, \mathrm{R}, \mathrm{K}\right) * \mathrm{SD}(\mathrm{X} 1)$

$\mathrm{X} 2=\mathrm{X} 1+\mathrm{S}$

$\mathrm{F} 2=\mathrm{DUN}(\mathrm{Q} * \mathrm{X} 2, \mathrm{R}, \mathrm{K}) * \mathrm{SD}(\mathrm{X} 2)$

$\mathrm{SUB}=-\mathrm{S} / 3 \cdot{ }^{*}\left(\mathrm{~F} 0+4 \cdot{ }^{*} \mathrm{~F} 1+\mathrm{F} 2\right)$

$\mathrm{A} 2=\mathrm{A} 2+\mathrm{SUB}$

IF(A2/SUB.GT.10E7)GOTO 6

$\mathrm{X} 0=\mathrm{X} 2$

$\mathrm{F} 0=\mathrm{F} 2$

$5 \quad \mathrm{~S}=\mathrm{S}^{*} \mathrm{XINC}$

$6 \quad \mathrm{PDUN}=1.0-\mathrm{A} 1-\mathrm{A} 2$

IF(PDUN.LT.0.)PDUN=0.

RETURN

$7 \quad$ PDUN=1. - DUN $(Q, R, K)$

END

C

C

FUNCTION DUN(Q,R,K)

C SOLVES INNER INTEGRAL USING SIMPSONS RULE

C WIDTH OF FIT PARABOLAS IS INCREASED EACH STEP

C INTEGRATION STOPS WHEN SUBAREA/AREA IS LESS THAN 1 E-6

C DISTRIBUTION IS SYMMETR IC SO THF INTEGR AL FROM 0 TO INFINITY

C IS DOUBLED FOR SOLUTION

C 


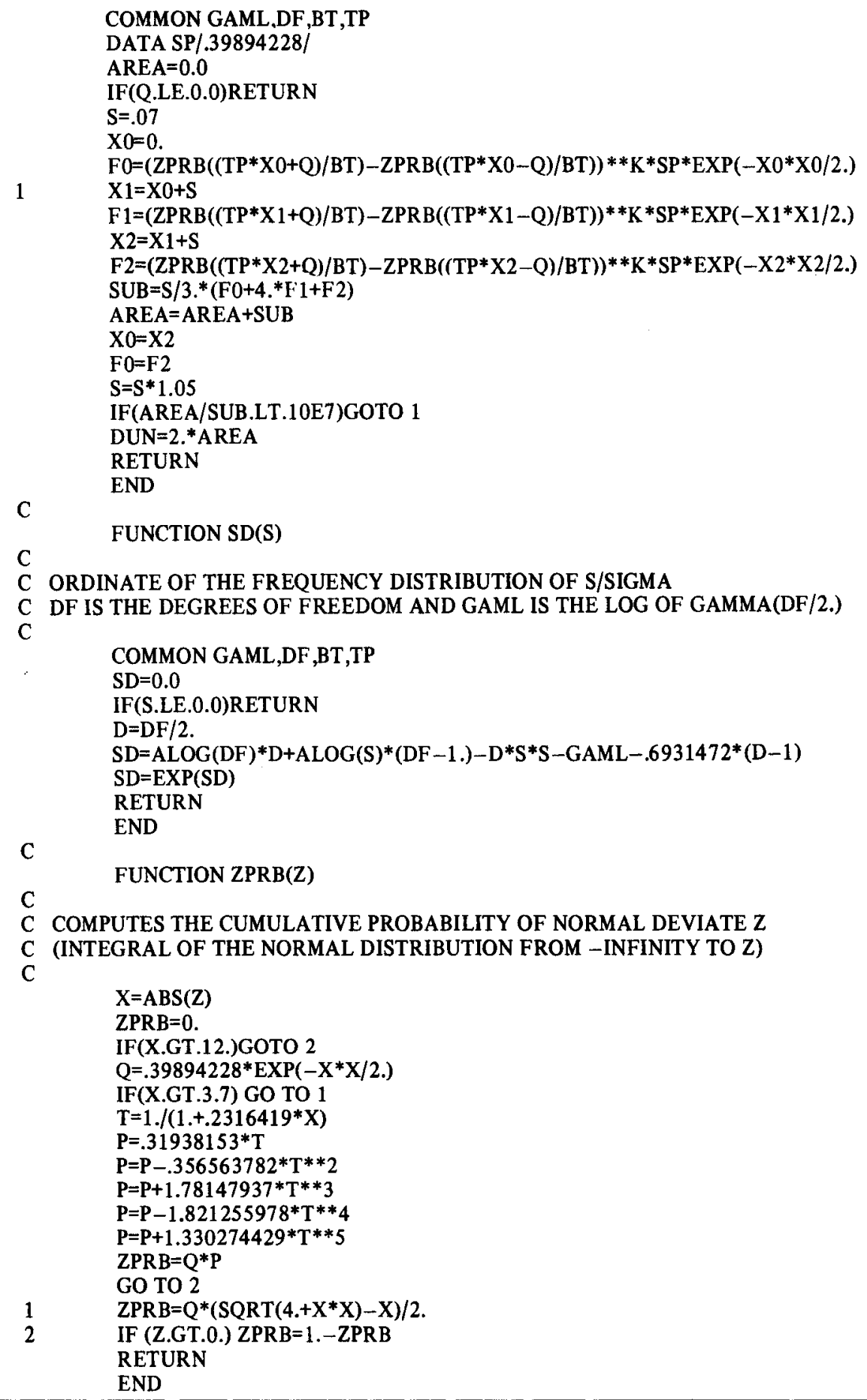

